The Astrophysical Journal, 677:1132-1139, 2008 April 20

(C) 2008. The American Astronomical Society. All rights reserved. Printed in U.S.A.

\title{
LABORATORY AND ASTRONOMICAL DETECTION OF THE NEGATIVE MOLECULAR ION C ${ }_{3}{ }^{-}$

\author{
P. Thaddeus, ${ }^{1}$ C. A. Gottlieb, ${ }^{1}$ H. Gupta, ${ }^{1,2}$ S. Brünken, ${ }^{1}$ M. C. McCarthy, ${ }^{1}$ \\ M. Agúndez, ${ }^{3}$ M. Guélin, ${ }^{4}$ and J. Cernicharo ${ }^{3}$ \\ Received 2007 November 21; accepted 2007 December 19
}

\begin{abstract}
The negative molecular ion $\mathrm{C}_{3} \mathrm{~N}^{-}$has been detected at millimeter wavelengths in a low-pressure laboratory discharge, and then with frequencies derived from the laboratory data in the molecular envelope of IRC +10216 . Spectroscopic constants derived from laboratory measurements of 12 transitions between 97 and $378 \mathrm{GHz}$ allow the rotational spectrum to be calculated well into the submillimeter-wave band to $0.03 \mathrm{~km} \mathrm{~s}^{-1}$ or better in equivalent radial velocity. Four transitions of $\mathrm{C}_{3} \mathrm{~N}^{-}$were detected in IRC+10216 with the IRAM $30 \mathrm{~m}$ telescope at precisely the frequencies calculated from the laboratory measurements. The column density of $\mathrm{C}_{3} \mathrm{~N}^{-}$is $0.5 \%$ that of $\mathrm{C}_{3} \mathrm{~N}$, or approximately 20 times greater than that of $\mathrm{C}_{4} \mathrm{H}^{-}$relative to $\mathrm{C}_{4} \mathrm{H}$. The $\mathrm{C}_{3} \mathrm{~N}^{-}$abundance in IRC+10216 is compared with a chemical model calculation by Petrie \& Herbst. An upper limit in TMC-1 for $\mathrm{C}_{3} \mathrm{~N}^{-}$relative to $\mathrm{C}_{3} \mathrm{~N}(<0.8 \%)$ and a limit for $\mathrm{C}_{4} \mathrm{H}^{-}$relative to $\mathrm{C}_{4} \mathrm{H}(<0.004 \%)$ that is 5 times lower than that found in $\mathrm{IRC}+10216$, were obtained from observations with the NRAO $100 \mathrm{~m}$ Green Bank Telescope (GBT). The fairly high concentration of $\mathrm{C}_{3} \mathrm{~N}^{-}$achieved in the laboratory implies that other molecular anions containing the $\mathrm{CN}$ group may be within reach.
\end{abstract}

Subject headings: ISM: molecules — line: identification - molecular data — molecular processes radio lines: ISM

\section{INTRODUCTION}

The carbon chain radicals $\mathrm{C}_{3} \mathrm{~N}$ and $\mathrm{C}_{4} \mathrm{H}$, similar linear molecules with open shell ${ }^{2} \Sigma$ electronic ground states and spin doubling and hyperfine structure in their rotational spectra, were identified 30 years ago prior to laboratory detection in the expanding molecular shell of the well-known evolved carbon star IRC+10216 (Guélin \& Thaddeus 1977; Guélin et al. 1978). In the absence of laboratory data, the identifications were based on the rotational constants derived from the observations, which were within about $1 \%$ of those predicted, and on the well resolved spin doubling, which was about that expected. $\mathrm{C}_{3} \mathrm{~N}$ was identified first, and the subsequent observation of the predicted $\mathrm{C}_{4} \mathrm{H}$ was evidence that the assignment was correct. Several years later laboratory identification conclusively confirmed both assignments (Gottlieb et al. 1983).

Positive molecular ions have long been known in the interstellar gas, starting with $\mathrm{CH}^{+}$, one of the first three interstellar molecules (Douglas \& Herzberg 1941), and 14 are now known. Negative molecular ions, however, have only been known for just over one year; the first, $\mathrm{C}_{6} \mathrm{H}^{-}$, was shown on the basis of laboratory measurements (McCarthy et al. 2006) to be the carrier of an unidentified series of lines in IRC+10216 (Kawaguchi et al. 1995). $\mathrm{C}_{4} \mathrm{H}^{-}$was identified in a gas discharge in this laboratory in 2006 October (Gupta et al. 2007), and with rest frequencies in

\footnotetext{
1 Harvard-Smithsonian Center for Astrophysics, 60 Garden Street, Cambridge, MA 02138, and School of Engineering and Applied Sciences, Harvard University, 29 Oxford Street, Cambridge, MA 02138; pthaddeus@cfa.harvard.edu, cgottlieb@cfa.harvard.edu, hgupta@cfa.harvard.edu, sbruenken@cfa.harvard.edu, mccarthy@cfa.harvard.edu.

2 Institute for Theoretical Chemistry, Departments of Chemistry and Biochemistry, The University of Texas at Austin, TX 78712.

3 Department of Molecular and Infrared Astrophysics, Instituto de Estructura de la Materia, CSIC, Serrano 121,28006 Madrid, Spain; marce@damir.iem.csic.es, cerni@damir.iem.csic.es.

4 Insitut de Radioastronomie Millimétrique, 300 rue de la Piscine, 38406 St. Martin d'Hères, France, and LERMA/Ecole Normale Superieure, 24 rue Lohmond, 75231 Paris, France; guelin@iram.fr.
}

hand was then quickly found in the millimeter-wave spectrum of IRC +10216 with the IRAM $30 \mathrm{~m}$ telescope (Cernicharo et al. 2007). Searches both in the laboratory and in space for the isoelectronic $\mathrm{C}_{3} \mathrm{~N}^{-}$were then undertaken, and both have now succeeded. It is the purpose of the present paper to describe the laboratory and astronomical identification of this new negative ion.

\section{LABORATORY AND ASTRONOMICAL OBSERVATIONS}

\subsection{Laboratory}

We previously detected $\mathrm{C}_{4} \mathrm{H}^{-}$in both the millimeter-wave band with the free space spectrometer in this laboratory, and in the centimeter-wave band with the Fourier-transform microwave spectrometer, but so far we have only been able to observe $\mathrm{C}_{3} \mathrm{~N}^{-}$ with the free space instrument. The reason for this difference is unclear but, as discussed below, it may be fundamental, the result of the quite different discharge conditions employed in the two instruments. Twelve rotational lines between 97 and $378 \mathrm{GHz}$ have been measured; Table 1 summarizes the data. The best-fit constants $B$ and $D$ in Table 2 reproduce the measured frequencies to an rms of $19 \mathrm{kHz}$, which is comparable to the measurement uncertainties; they allow the rotational spectrum to as high as $500 \mathrm{GHz}$ to be calculated to $0.03 \mathrm{~km} \mathrm{~s}^{-1}$ in radial velocity, which is adequate for deep spectral line searches in nearly all astronomical sources. (The sixth-order centrifugal distortion constant $H$ has not been determined, but to judge from the measured sixthorder term of $\mathrm{HC}_{3} \mathrm{~N}$ [Thorwirth et al. 2000], its effect on line frequencies even as high as $500 \mathrm{GHz}$ is almost negligible.)

Our first attempts to find $\mathrm{C}_{3} \mathrm{~N}^{-}$were extremely frustrating, and it was only after two surveys failed to yield evidence for this ion that a third independent search under different discharge conditions met with success. Each survey covered about $1.2 \mathrm{GHz}$ of the millimeter-wave spectrum, and required about $10 \mathrm{hr}$ of observation. The crucial parameter turned out to be the current in the large glow discharge of the free space spectrometer, which in the first two surveys was set at 75-100 mA, the current which yields the strongest lines of $\mathrm{C}_{3} \mathrm{~N}$, but for $\mathrm{C}_{3} \mathrm{~N}^{-}$turned out to be too high 
TABLE 1

Laboratory Frequencies of $\mathrm{C}_{3} \mathrm{~N}^{-}$

\begin{tabular}{|c|c|c|}
\hline Transition & $\begin{array}{c}\text { Frequency }^{\mathrm{a}} \\
\quad(\mathrm{MHz})\end{array}$ & $\begin{array}{l}O-C^{\mathrm{b}} \\
(\mathrm{kHz})\end{array}$ \\
\hline 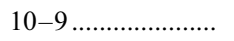 & $97,029.656$ & -37 \\
\hline $12-11$..................... & $116,434.180$ & -3 \\
\hline 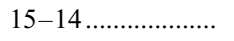 & $145,539.368$ & -27 \\
\hline $16-15 \ldots \ldots \ldots \ldots \ldots$ & $155,240.672$ & 11 \\
\hline $19-18 \ldots \ldots \ldots \ldots \ldots$ & $184,342.811$ & 0 \\
\hline $23-22 \ldots \ldots \ldots \ldots \ldots \ldots$ & $223,141.256$ & 34 \\
\hline $25-24 \ldots \ldots \ldots \ldots \ldots \ldots$ & $242,538.225$ & 3 \\
\hline $27-26 \ldots \ldots \ldots \ldots \ldots$ & $261,933.577$ & 2 \\
\hline $28-27 \ldots \ldots \ldots \ldots \ldots \ldots . . .$. & $271,630.585$ & -8 \\
\hline $29-28 \ldots \ldots \ldots \ldots \ldots . . . . .$. & $281,327.147$ & -4 \\
\hline $35-34 \ldots \ldots \ldots \ldots \ldots$ & $339,495.912$ & 19 \\
\hline 39-38 …….............. & $378,263.734$ & -16 \\
\hline
\end{tabular}

by a factor of 4-5. We were undeterred by our initial failure, because $\mathrm{C}_{3} \mathrm{~N}^{-}$appeared to be an extremely good candidate for both laboratory and astronomical detection: its dipole moment is calculated to be quite large, 3.1 D (this work; Kolos et al. 2008), and its electron affinity (the electron binding energy) is one of the highest of any polyatomic molecule, $4.59 \pm 0.25 \mathrm{eV}$ according to Graupner et al. (2006).

We first searched for lines of $\mathrm{C}_{3} \mathrm{~N}^{-}$between 329 and $359 \mathrm{GHz}$ in a $100 \mathrm{~mA}$ discharge through a mixture of commercially available gases that yielded an optimum concentration of $\mathrm{C}_{3} \mathrm{~N}$ : cyanogen ( $\mathrm{NCCN}, 25 \%)$, acteylene $\left(\mathrm{C}_{2} \mathrm{H}_{2}, 25 \%\right)$, and nitrogen $\left(\mathrm{N}_{2}\right.$, $50 \%$ ) with the walls of the discharge cell cooled to $200 \mathrm{~K}$. Yielding no evidence for $\mathrm{C}_{3} \mathrm{~N}^{-}$, the commercial gases were replaced with cyanoacetylene $\left(\mathrm{HC}_{3} \mathrm{~N}\right.$, synthesized by the procedure described in Appendix A), because it had been shown that $\mathrm{HC}_{3} \mathrm{~N}$ is the best source of the $\mathrm{C}_{3} \mathrm{~N}$ radical (Gottlieb et al. 1983; McCarthy et al. 1995) and the $\mathrm{C}_{3} \mathrm{~N}^{-}$anion is produced by dissociative electron attachment to $\mathrm{HC}_{3} \mathrm{~N}$ at very low electron energies (1.6 eV; Graupner et al. 2006). In the second search, three transitions were covered in a fairly high current discharge $(75 \mathrm{~mA})$ through $\mathrm{HC}_{3} \mathrm{~N}(20 \%)$ and $\mathrm{Ar}(80 \%)$ cooled to $200 \mathrm{~K}$; again, no lines attributable to $\mathrm{C}_{3} \mathrm{~N}^{-}$appeared. Lines of $\mathrm{C}_{3} \mathrm{~N}^{-}$were finally observed in the third search, which was done with the same mixture of gases as for the previous one, but at a lower current $(20 \mathrm{~mA})$. The total pressure was about 15 mtorr when the walls of the discharge cell were cooled to $250 \mathrm{~K}$.

TABLE 2

Seectroscopic Constants of $\mathrm{C}_{3} \mathrm{~N}^{-}$

\begin{tabular}{|c|c|c|c|c|}
\hline \multirow[b]{2}{*}{ Constant } & \multirow[b]{2}{*}{ LABORATORY } & \multirow[b]{2}{*}{ AstRONOMICAL } & \multicolumn{2}{|c|}{ Theoretical } \\
\hline & & & This Work $^{\mathrm{a}}$ & $\mathrm{KGB}^{\mathrm{b}}$ \\
\hline В & $4851.62183(20)$ & 4851.61(3) & 4848 & 4850 \\
\hline $10^{6} \mathrm{D} \ldots \ldots \ldots \ldots \ldots \ldots$ & $685.92(10)$ & $700(100)$ & 627 & 628 \\
\hline$e Q q \ldots \ldots \ldots \ldots \ldots$ & $\ldots$ & $\ldots$ & -3.3 & $\ldots$ \\
\hline
\end{tabular}

Note.-Values are given in MHz.

${ }^{\mathrm{a}} B_{e}(4852.7 \mathrm{MHz})$ from a CCSD(T)/aug-cc-pVQZ calculation; the vibrationrotation correction $(4.6 \mathrm{MHz})$ and $D$ were calculated at the $\operatorname{CCSD}(\mathrm{T}) / \mathrm{cc}-\mathrm{pVTZ}$ level of theory.

${ }^{\mathrm{b}} B_{e}(4850.6 \mathrm{MHz})$ and $D$ from a $\operatorname{CCSD}(\mathrm{T}) /$ aug-cc-pCV5Z calculation; the vibration-rotation correction $(0.6 \mathrm{MHz})$ was calculated at the $\operatorname{CCSD}(\mathrm{T}) /$ aug-cc-pVQZ level of theory (Kolos et al. 2008).

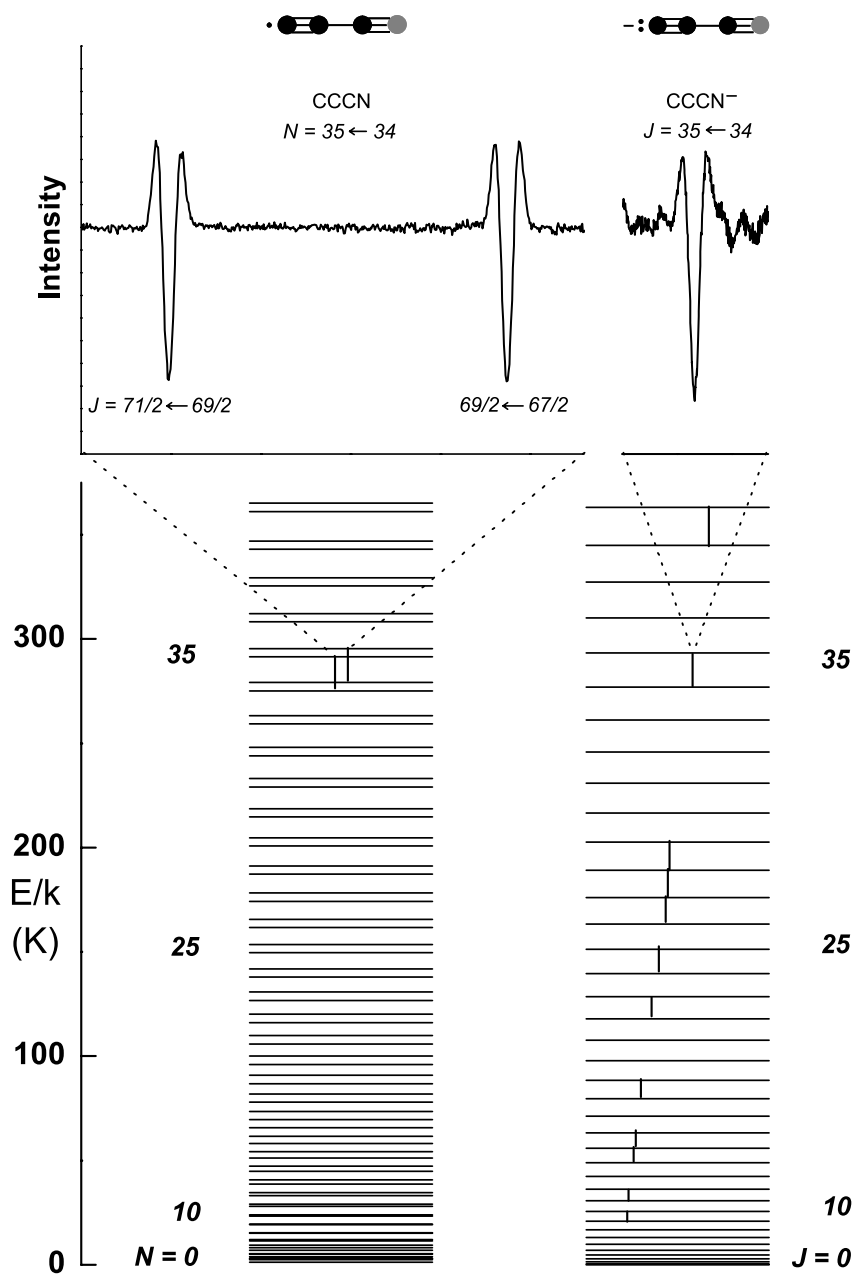

FIG. 1.-Sample laboratory spectra and rotational energy levels of $\mathrm{C}_{3} \mathrm{~N}$ and $\mathrm{C}_{3} \mathrm{~N}^{-}$, illustrating the collapse of the spin doublet fine structure of $\mathrm{C}_{3} \mathrm{~N}$ on electron attachment. Left: $N=35 \leftarrow 34$ transition of $\mathrm{C}_{3} \mathrm{~N}$ observed with an integration time of 3 minutes, showing the well-resolved spin rotation doublets. The separation of the spin doublets are magnified 6000 -fold in the energy level diagram. Simultaneous frequency and Zeeman modulation were used to remove background lines; owing to the modulation employed the instrumental line shape is approximately the second derivative of a Lorentzian. Right: Corresponding transition of $\mathrm{C}_{3} \mathrm{~N}^{-}$observed in the same discharge with an integration time of 10 minutes. The intensity scale is magnified with respect to that of $\mathrm{C}_{3} \mathrm{~N}$. The measured transitions are indicated by solid vertical lines.

The density of background lines in the $\mathrm{HC}_{3} \mathrm{~N}$ discharge was quite high. Typically one line every $10 \mathrm{MHz}$ was encountered at an intensity comparable to that of $\mathrm{C}_{3} \mathrm{~N}^{-}$, or about 50 background lines at each transition surveyed. The lines of $\mathrm{C}_{3} \mathrm{~N}^{-}$could be distinguished from this clutter of unrelated lines because transitions in the closed-shell ${ }^{1} \Sigma$ electronic ground state are closely harmonic in frequency, and the theoretical centrifugal distortion constant $(D)$ is sufficiently accurate to predict successive transitions to within the pressure broadened line width $(1.2 \mathrm{MHz})$. Two successive harmonically related lines at 262 and $272 \mathrm{GHz}$, assigned to the $J=27-26$ and $28-27$ transitions, yielded a preliminary estimate of the rotational constant $B$. Additional lines with comparable intensities were then observed at both higher and lower frequencies, confirming the assignment.

The highest concentration of $\mathrm{C}_{3} \mathrm{~N}^{-}$was observed with a discharge current $(20 \mathrm{~mA})$ that was 5 times lower than that which was best for $\mathrm{C}_{3} \mathrm{~N}(100 \mathrm{~mA})$. The line at $339 \mathrm{GHz}$ was then about 100 times weaker than the corresponding transition of $\mathrm{C}_{3} \mathrm{~N}$ (summed over both spin components; see Fig. 1). Owing to the smaller 


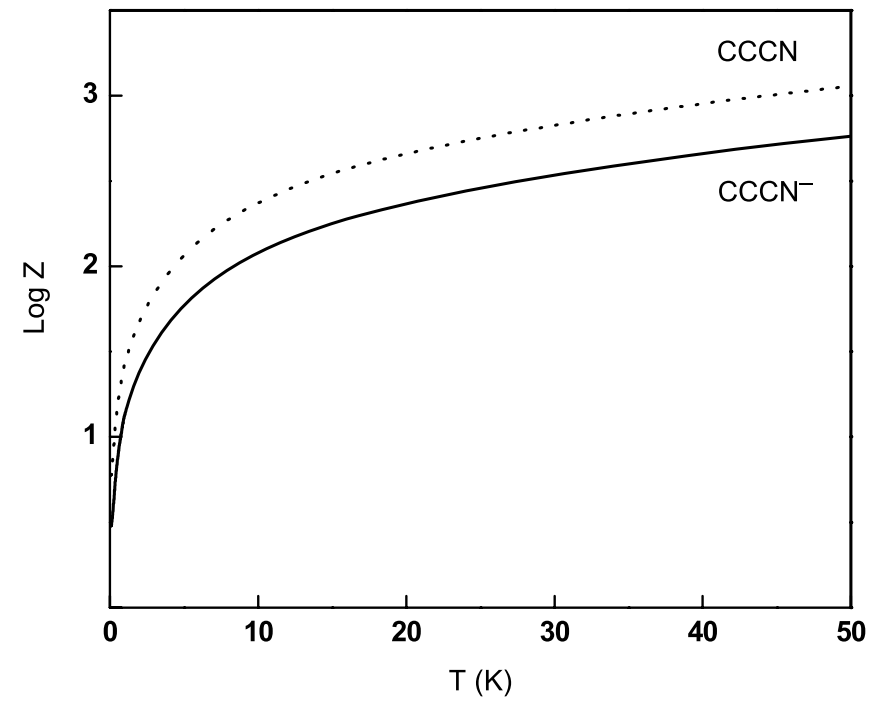

FIG. 2.-Rotational partition function $(Z)$ of $\mathrm{C}_{3} \mathrm{~N}_{\text {and }} \mathrm{C}_{3} \mathrm{~N}^{-}$vs. temperature $(T)$.

partition function and larger dipole moment, lines of $\mathrm{C}_{3} \mathrm{~N}^{-}$are 2.4 times more intense than those of $\mathrm{C}_{3} \mathrm{~N}$ per unit abundance (Fig. 2). The concentration of $\mathrm{C}_{3} \mathrm{~N}^{-}$in our discharge $\left(3 \times 10^{7} \mathrm{~cm}^{-3}\right)$, corresponding to a mole fraction of $5 \times 10^{-8}$, is $\leq 0.001 \%$ that of $\mathrm{HC}_{3} \mathrm{~N}$ under the conditions in which lines of the anion are most intense. The anion to radical concentration-about $2 \%$ is comparable to that of $\mathrm{CN}^{-}$(Gottlieb et al. 2007), but the mole fraction of $\mathrm{C}_{3} \mathrm{~N}^{-}$is about 100 times smaller than that of $\mathrm{CN}^{-}$in the respective discharges. Following detection of $\mathrm{C}_{3} \mathrm{~N}^{-}$in a discharge through $\mathrm{HC}_{3} \mathrm{~N}$ (with either $\mathrm{Ar}$ or $\mathrm{N}_{2}$ as the carrier gas), other known sources of $\mathrm{C}_{3} \mathrm{~N}$ were examined for evidence of the anion. Lines of $\mathrm{C}_{3} \mathrm{~N}^{-}$were observed in low-current $(20 \mathrm{~mA})$ discharges through $\mathrm{HCCH} / \mathrm{N}_{2}$ and $\mathrm{HCCH} / \mathrm{N}_{2} / \mathrm{NCCN}$, but not through $\mathrm{NCCN}$ with either Ar or $\mathrm{N}_{2}$ as the carrier. Although the latter discharge is a good source of the radical, the anion was not observed because of the absence of hydrogen.

The evidence that $\mathrm{C}_{3} \mathrm{~N}^{-}$is the carrier of the series of lines in Table 1 is overwhelming. As mentioned, the assigned lines are closely harmonic in frequency, and show no evidence of fine or hyperfine structure, as expected for high rotational transitions of a molecule in a ${ }^{1} \Sigma$ ground electronic state. The rotational constant $(B)$ is only $2 \%$ smaller than that of $\mathrm{C}_{3} \mathrm{~N}$, about as expected, because electron attachment to carbon chains generally results in only a slight decrease in $B$. There is no evidence for nitrogen quadrupole hyperfine structure and none is expected, because hyperfine structure (hfs; $<10 \mathrm{kHz}$ at $97 \mathrm{GHz}$ ) is much less than the pressure broadened line width. Although we did not directly rule out $\mathrm{H}$ as a possible constituent by observing the same series of lines in a discharge through $\mathrm{DC}_{3} \mathrm{~N}$, the addition of an $\mathrm{H}$ atom at the end of the chain would yield a rotational constant that is too small; for example, $B$ for $\mathrm{HC}_{3} \mathrm{~N}$ is $6 \%$ smaller than that of the carrier of the new series of lines.

The spectroscopic constants provide strong additional evidence in support of the assignment. First, the measured rotational constant is within $0.1 \%$ of that predicted by two independent highlevel quantum calculations, and the centrifugal distortion $(D)$ is in excellent agreement with that calculated. Second, other possible carriers such as the carbon-13 or nitrogen-15 isotopic species of the $\mathrm{C}_{3} \mathrm{~N}$ radical are ruled out because: (1) the rotational spectra of these have been measured (McCarthy et al. 1995); and (2) the spectra of the isotopic species of the radical would consist of symmetrical spin doublets separated by about $19 \mathrm{MHz}$, rather than the single series of lines observed. Third, vibrationally excited

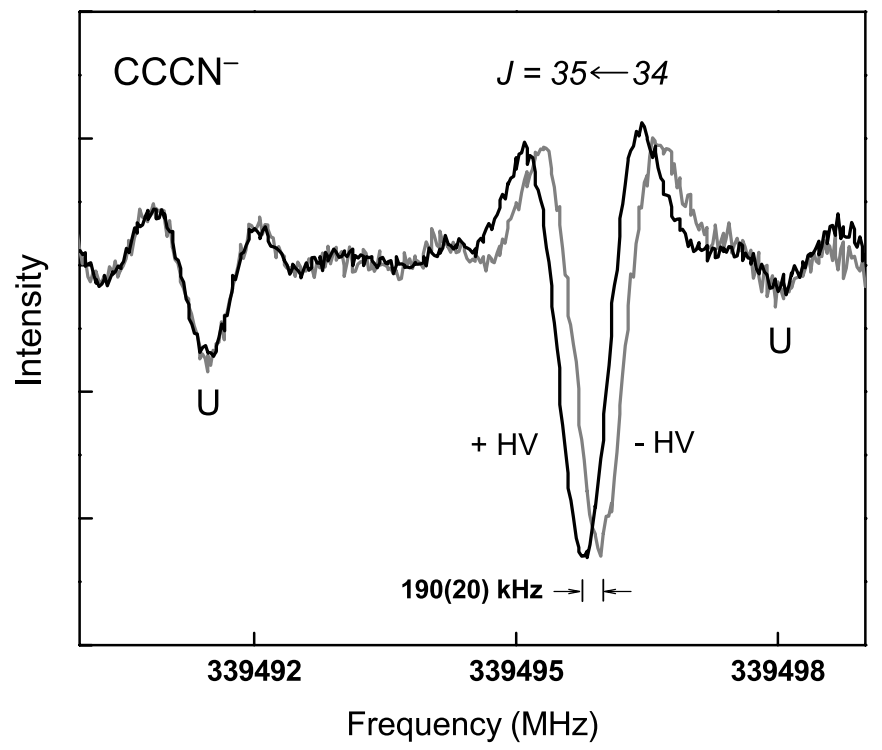

FIG. 3.- Ion drift measurement of $\mathrm{C}_{3} \mathrm{~N}^{-}$. The $J=35 \leftarrow 34$ absorption line of $\mathrm{C}_{3} \mathrm{~N}^{-}$with either positive or negative high voltage (HV) applied to the electrode near the radiation source; the electrode near the detector was held at ground. The integration time for each spectrum was approximately 30 minutes. The frequency shift derived here $(95 \pm 10 \mathrm{kHz})$ corresponds to an axial ion drift velocity of $80 \pm 10 \mathrm{~m} \mathrm{~s}^{-1}$. The weak features marked $\mathrm{U}$ are from unassigned neutral molecules produced in the discharge.

$\mathrm{C}_{3} \mathrm{~N}$ is ruled out for several reasons: the rotational constants in the low-lying bending vibrational levels are close to that of the ground state (Mikami et al. 1989); although the rotational spectra in the stretching levels of $\mathrm{C}_{3} \mathrm{~N}$ have not been measured, by analogy with other linear polyatomic molecules such as $\mathrm{HC}_{3} \mathrm{~N}$, the rotational constants are expected to be within $1 \%$ of that of the ground state; and the symmetry of the lowest stretching levels in $\mathrm{C}_{3} \mathrm{~N}$ is ${ }^{2} \Sigma$, so the spectra will consist of well-resolved spin doublets rather than a single series of lines. Fourth, the $\mathrm{C}_{3} \mathrm{~N}^{+}$cation is ruled out because three published quantum calculations predict it to have a triplet electronic ground state (Harland \& Maclagan 1987; Ding et al. 1998; Kolos et al. 2008). The rotational spectrum of $\mathrm{C}_{3} \mathrm{~N}^{+}$would then consist of three well-resolved fine-structure components of comparable intensity, rather than the observed single series of harmonic lines.

Finally, direct determination of the charge of the carrier provides conclusive confirmation of our assignment. Ions are accelerated in the positive column of a glow discharge owing to the axial electric field [typically $(5-15) \mathrm{V} \mathrm{cm}^{-1}$; Stephenson \& Saykally 2005]. A measurable Doppler shift in the line frequency was observed when the millimeter-wave radiation made a single pass through the discharge cell (normally a double pass is employed to enhance sensitivity). The sign of the shift then changed on reversal of the cathode and anode potentials, as expected for a negative ion (Fig. 3$)$. The observed ion drift velocity $\left(v_{\mathrm{da}}=\right.$ $80 \pm 10 \mathrm{~ms}^{-1}$ ) is within $10 \%$ of that inferred from earlier measurements of $\mathrm{CN}^{-}$in a similar discharge (Gottlieb et al. 2007) on the assumption that $v_{\mathrm{da}}$ is inversely proportional to the square root of the mass of the ion.

\subsection{Astronomical

$$
\text { 2.2.1. IRC+10216 }
$$

The recent detection of $\mathrm{C}_{4} \mathrm{H}^{-}$in IRC+10216 with the IRAM $30 \mathrm{~m}$ telescope implies that the isoelectronic $\mathrm{C}_{3} \mathrm{~N}^{-}$might be detectable in this source. Before undertaking new observations, we examined spectra of this source obtained in a deep survey for 

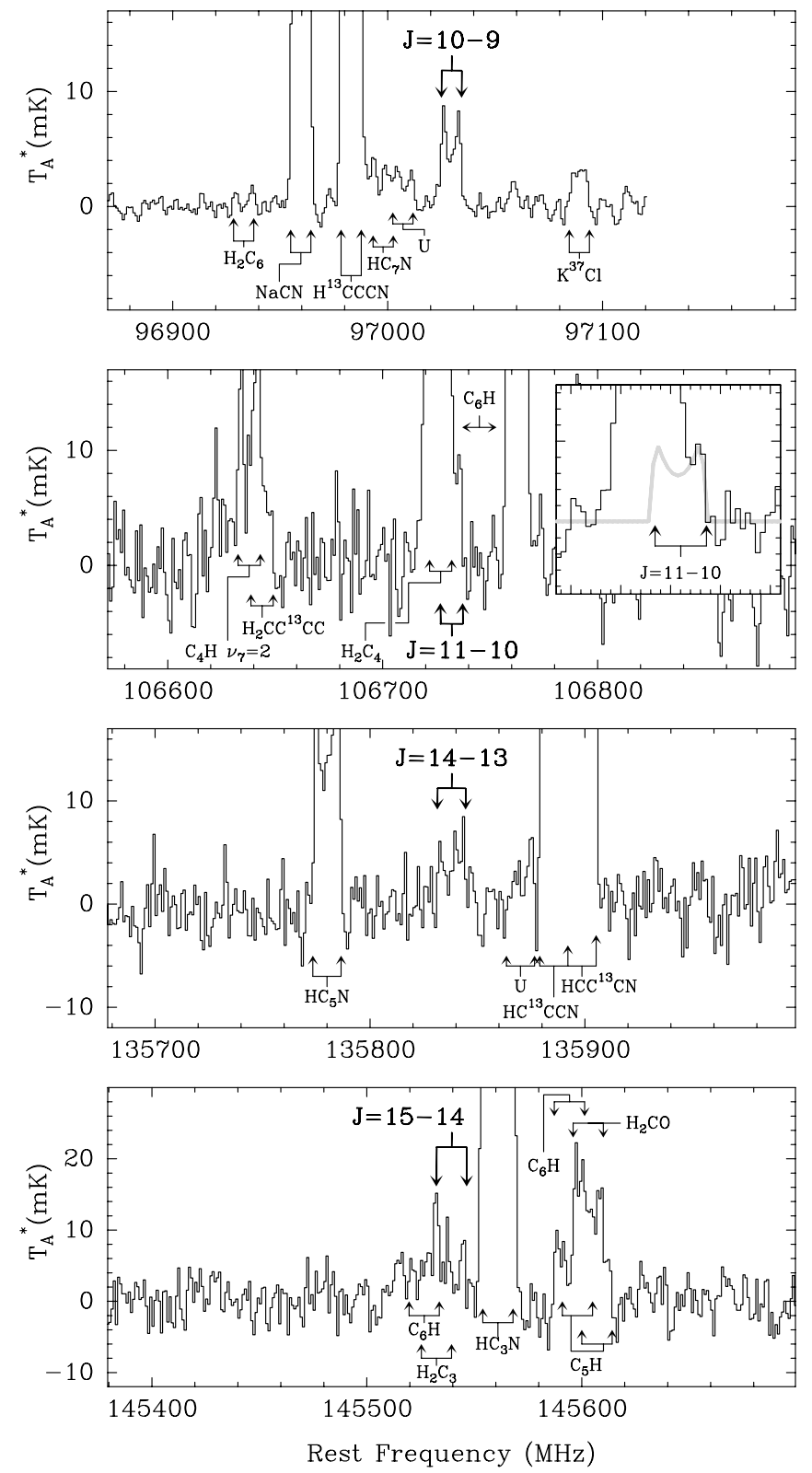

Fig. 4.-Four transitions of $\mathrm{C}_{3} \mathrm{~N}^{-}$observed toward IRC+10216. The red and blue edges of the cusped line shapes are indicated by vertical arrows. The $J=$ $11-10$ line at $106.7 \mathrm{GHz}$ is blended with an intense line of $\mathrm{C}_{6} \mathrm{H}$ (see simulated profile in insert), and the $J=15-14$ line at $145.5 \mathrm{GHz}$ is partially blended with very weak lines of $1-\mathrm{H}_{2} \mathrm{C}_{3}$ and $\mathrm{C}_{6} \mathrm{H}$. The antenna temperature scale is corrected for atmosphere attenuation and spillover losses $\left(T_{A}^{*}\right)$, the spectral resolution is $1 \mathrm{MHz}$, and the frequency axis is relative to a systemic velocity of $-26.5 \mathrm{~km} \mathrm{~s}^{-1}$.

new molecules in the $3 \mathrm{~mm}$ band (J. Cernicharo et al. 2008, in preparation). This survey contains a number of lines that could not be assigned to any known carrier, including two of similar intensity which agree in frequency to better than $0.5 \mathrm{MHz}$ with the $J=10-9(97,030 \mathrm{MHz})$ and $11-10(106,732 \mathrm{MHz})$ transitions of $\mathrm{C}_{3} \mathrm{~N}^{-}$. The evidence for $\mathrm{C}_{3} \mathrm{~N}^{-}$is compelling, because the density of lines in our $3 \mathrm{~mm}$ spectral survey with intensities $\geq 5 \mathrm{mK}$ is only about one every $30 \mathrm{MHz}$, and the number of lines with $T_{A}^{*} \sim 7 \mathrm{mK}$ is even less: roughly one every $100 \mathrm{MHz}$. Although three other transitions of $\mathrm{C}_{3} \mathrm{~N}^{-}$were also covered in this band (at 77,625, 87,327, and 116,434 MHz), these are either blended with intense background lines [e.g., the $(N, J, F)=$ $(1,3 / 2,1-0,1 / 2,0)$ component of $\mathrm{C}_{2} \mathrm{H}$ at $87,328 \mathrm{MHz}$, or they lie at frequencies where the noise temperatures of the receivers
TABLE 3

Observed Line Parameters of $\mathrm{C}_{3} \mathrm{~N}^{-}$IN IRC+10216

\begin{tabular}{|c|c|c|c|c|}
\hline \multirow[b]{2}{*}{ Transition $J^{\prime}-J$} & \multicolumn{2}{|c|}{ FREQUENCY (MHz) } & \multirow{2}{*}{$\begin{array}{c}\int T_{A}^{*} d v \\
\left(\mathrm{~K} \mathrm{~km} \mathrm{~s}^{-1}\right)\end{array}$} & \multirow{2}{*}{$\begin{array}{c}V_{\exp } \\
\left(\mathrm{km} \mathrm{s}^{-1}\right)\end{array}$} \\
\hline & Calculated $^{\mathrm{a}}$ & Observed & & \\
\hline $10-9$. & 97029.693 & $97029.5(3)$ & $0.183(12)$ & $14.1(3)$ \\
\hline $11-10 \ldots$ & 106732.028 & $106731.5(8)$ & $0.224(20)^{\mathrm{b}}$ & $14.5^{\mathrm{c}}$ \\
\hline $14-13$......................... & 135837.883 & $135837.9(6)$ & $0.128(20)$ & $14.1(6)$ \\
\hline 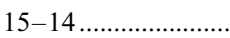 & 145539.395 & $145538.6(10)$ & $0.165(40)^{\mathrm{b}}$ & $14.5^{\mathrm{c}}$ \\
\hline
\end{tabular}

Notes.-The numbers in parentheses are the $1 \sigma$ uncertainties in units of the last digits. The observed line frequencies are computed for a source velocity $v_{\mathrm{LSR}}=-26.5 \mathrm{~km} \mathrm{~s}^{-1}$.

a Calculated with the spectroscopic constants derived from the laboratory measurements (Table 2).

b Partially blended line.

c Terminal velocity constrained to $14.5 \mathrm{~km} \mathrm{~s}^{-1}$.

are high. To confirm our tentative identification of $\mathrm{C}_{3} \mathrm{~N}^{-}$, we then undertook observations in 2007 September and October of two additional transitions in the $2 \mathrm{~mm}$ wave band.

The observations in the $2 \mathrm{~mm}$ band were also made with the $30 \mathrm{~m}$ telescope. The dual-polarization receivers were operated in the single-sideband mode with a rejection of the upper sideband of about $18 \mathrm{~dB}$, as estimated from the intensities of strong lines. The back ends consisted of two 512 channel filter banks with $1 \mathrm{MHz}$ resolution. To ensure flat baselines, the secondary mirror was wobbled by $\pm 90^{\prime \prime}$ at a $0.5 \mathrm{~Hz}$ rate. The zenith sky opacity of $0.03-0.20$ resulted in a system noise temperature of $170-330 \mathrm{~K}$. The total integration time for each polarization in the position switching mode was $4 \mathrm{hr}$ at $135.8 \mathrm{GHz}$ and $2 \mathrm{hr}$ at $145.5 \mathrm{GHz}$, which yielded an rms noise of $2-3 \mathrm{mK}$ when the two polarizations were averaged.

Two lines of similar intensity $\left(T_{A}^{*} \sim 6 \mathrm{mK}\right)$ coincide in frequency with the $J=14-13(135,838 \mathrm{MHz})$ and $15-14(145,539 \mathrm{MHz})$ transitions of $\mathrm{C}_{3} \mathrm{~N}^{-}$. Although the line at $145.5 \mathrm{GHz}$ is partially blended with lines of $\mathrm{C}_{6} \mathrm{H}$ and $1-\mathrm{H}_{2} \mathrm{C}_{3}$, it could be assigned to $\mathrm{C}_{3} \mathrm{~N}^{-}$with some confidence, because the line width $\left(29 \mathrm{~km} \mathrm{~s}^{-1}\right)$ and cusped line shape - characteristic of molecular emission from the outer envelope of IRC +10216 - are similar to that of the line at $97 \mathrm{GHz}$, which was observed with excellent signal to noise and is free of contamination by background lines. All four lines are shown in Figure 4; the data are summarized in Table 3.

Figure 5 shows the rotational temperature diagrams for lines of $\mathrm{C}_{3} \mathrm{~N}^{-}$and $\mathrm{C}_{3} \mathrm{~N}$ observed in the IRAM $30 \mathrm{~m}$ spectral survey (Cernicharo et al. 2008, in preparation, 2000; Table 3, this work). The radius of the shell as determined from that of the neutral species is $10^{\prime \prime}-24^{\prime \prime}$ (see, e.g., Guélin et al. 1993), so line intensities have been corrected for beam dilution assuming a uniform source of radius $20^{\prime \prime}$. The rotational temperature $T_{\text {rot }}$ is the same for the anion and the radical to within the measurement uncertainties: $24 \pm 5 \mathrm{~K}$ for $\mathrm{C}_{3} \mathrm{~N}^{-}$and $29 \pm 2 \mathrm{~K}$ for $\mathrm{C}_{3} \mathrm{~N}$. The total column density across the shell is $(1.6 \pm 0.6) \times 10^{12} \mathrm{~cm}^{-2}$ for $\mathrm{C}_{3} \mathrm{~N}^{-}$ versus $(3.1 \pm 0.3) \times 10^{14} \mathrm{~cm}^{-2}$ for $\mathrm{C}_{3} \mathrm{~N}$. The abundance ratio $\left[\mathrm{C}_{3} \mathrm{~N}^{-}\right] /\left[\mathrm{C}_{3} \mathrm{~N}\right]$ of $0.52 \%$ is about 20 times larger than $\left[\mathrm{C}_{4} \mathrm{H}^{-}\right] /$ $\left[\mathrm{C}_{4} \mathrm{H}\right]$, but is 12 times smaller than $\left[\mathrm{C}_{6} \mathrm{H}^{-}\right] /\left[\mathrm{C}_{6} \mathrm{H}\right]($ Cernicharo et al. 2007) and 50-70 times smaller than $\left[\mathrm{C}_{8} \mathrm{H}^{-}\right] /\left[\mathrm{C}_{8} \mathrm{H}\right]$ in this source (Remijan et al. 2007; Kawaguchi et al. 2007).

There is little doubt that $\mathrm{C}_{3} \mathrm{~N}^{-}$is the carrier of the four assigned lines in IRC +10216 . As expected, the intensities of all four are similar, and there are no missing lines. The spectroscopic constants $B$ and $D$ are in excellent agreement with those from the laboratory (Table 2). The rotational temperature is the same as that of $\mathrm{C}_{3} \mathrm{~N}$, as expected (Fig. 5). The line observed with 


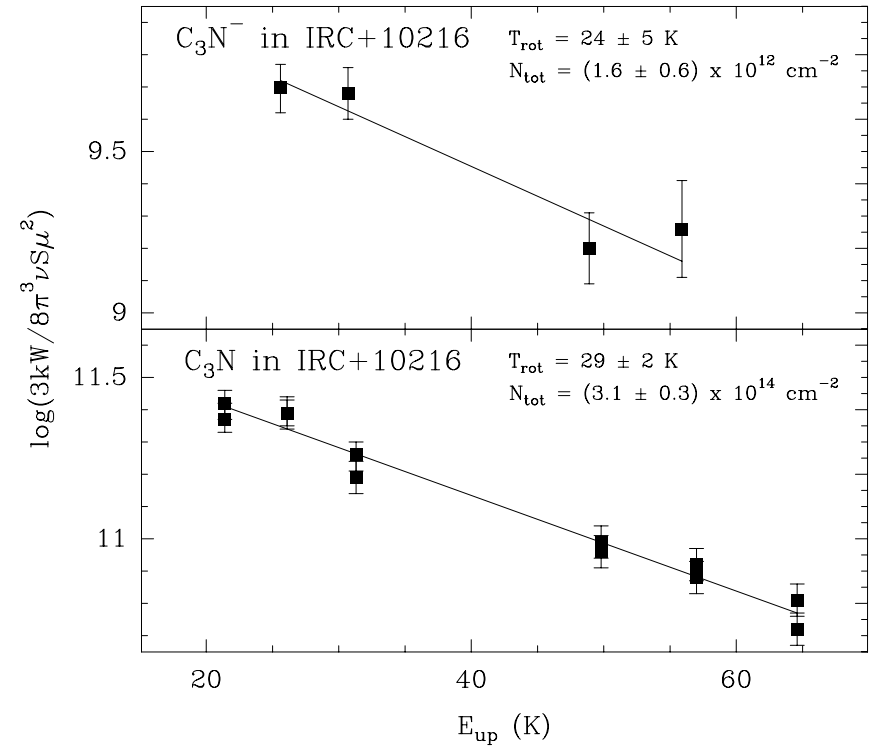

FIG. 5.- Rotational temperature diagram for $\mathrm{C}_{3} \mathrm{~N}^{-}$and $\mathrm{C}_{3} \mathrm{~N}$ in IRC+10216. The measured line intensities were corrected for beam dilution assuming a uniformly bright source of radius $20^{\prime \prime}$.

the highest signal-to-noise ratio $(J=10-9)$ is strongly cusped, confirming that $\mathrm{C}_{3} \mathrm{~N}^{-}$is confined to the same hollow shell as $\mathrm{C}_{3} \mathrm{~N}$ and the neutral acetylenic chain radicals, e.g., $\mathrm{C}_{3} \mathrm{H}, \mathrm{C}_{4} \mathrm{H}$, and $\mathrm{C}_{6} \mathrm{H}$.

\subsection{2. $T M C-1$}

The recent observations of $\mathrm{C}_{6} \mathrm{H}^{-}$and $\mathrm{C}_{8} \mathrm{H}^{-}$in TMC- 1 with abundances of a few percent that of the corresponding radical (McCarthy et al. 2006; Brünken et al. 2007), suggested that $\mathrm{C}_{3} \mathrm{~N}^{-}$ might be detected in this source. In 2007 October we did a simul- taneous search with the NRAO $100 \mathrm{~m}$ Green Bank Telescope (GBT) for the 2-1 lines of $\mathrm{C}_{3} \mathrm{~N}^{-}$and $\mathrm{C}_{4} \mathrm{H}^{-}$in TMC-1 near $19 \mathrm{GHz}$, and measurements of the corresponding lines of $\mathrm{C}_{3} \mathrm{~N}$ and $\mathrm{C}_{4} \mathrm{H}$. System temperatures with the $K$-band receiver were typically $30-50 \mathrm{~K}$. Spectra were acquired as before by position switching (Brünken et al. 2007), at a resolution of $6.1 \mathrm{kHz}$ across the $50 \mathrm{MHz}$ wide bands of the spectrometer.

Column densities were derived from the line parameters in Table 4 on the assumption that the rotational temperature is $5 \mathrm{~K}$. The column density of $\mathrm{C}_{3} \mathrm{~N}^{-}$in TMC-1 of $\leq 7 \times 10^{11} \mathrm{~cm}^{-2}$ is $\leq 0.8 \%$ of $\mathrm{C}_{3} \mathrm{~N}\left(9.5 \times 10^{13} \mathrm{~cm}^{-2}\right)$. Our limit for the $\mathrm{C}_{3} \mathrm{~N}^{-} / \mathrm{C}_{3} \mathrm{~N}$ ratio in TMC-1 is comparable to the ratio in IRC $+10216(0.52 \%$; $\S 2.2 .1)$. For $\mathrm{C}_{4} \mathrm{H}^{-}$our limit of the column density in TMC-1 $\left(\leq 2.3 \times 10^{10} \mathrm{~cm}^{-2}\right)$ is nearly 4 times lower than a preliminary estimate obtained by Brünken et al., and is 2 times lower than that determined in a search for the $83.8 \mathrm{GHz}$ line (Agúndez et al. 2008). The $\mathrm{C}_{4} \mathrm{H}^{-} / \mathrm{C}_{4} \mathrm{H}$ ratio in TMC- $1\left(<0.004 \%\right.$ for a $\mathrm{C}_{4} \mathrm{H}$ column density $^{5}$ of $\left.5.7 \times 10^{14} \mathrm{~cm}^{-2}\right)$ is 5 times lower than that found in IRC+10216 (0.02\%; Cernicharo et al. 2007). The upper limit for the anion to radical ratio for $\mathrm{C}_{4} \mathrm{H}$ is much lower than for $\mathrm{C}_{3} \mathrm{~N}$, because lines of $\mathrm{C}_{4} \mathrm{H}$ are several times more intense than those of $\mathrm{C}_{3} \mathrm{~N}$ in TMC-1 and the spectroscopic enhancement for $\mathrm{C}_{4} \mathrm{H}^{-}(100$; Gupta et al. 2007) is about 40 times greater than for $\mathrm{C}_{3} \mathrm{~N}^{-}(2.4$; see Appendix B).

\section{DISCUSSION}

Our laboratory search for $\mathrm{C}_{3} \mathrm{~N}^{-}$was guided by high-level quantum calculations of the structure of this anion. The equilibrium geometry was obtained at the coupled cluster $[\operatorname{CCSD}(\mathrm{T})]$ level of theory with a large basis set. The anharmonic force field calculated by the method described by Stanton \& Gauss (2000) was

\footnotetext{
5 There is a typographical error for the $\mathrm{C}_{4} \mathrm{H}$ column density in Table 2 of Brünken et al. (2007). The correct value is $6.1 \times 10^{14} \mathrm{~cm}^{-2}$.
}

TABLE 4

Observed Line Parameters of $\mathrm{C}_{3} \mathrm{~N}$ and $\mathrm{C}_{4} \mathrm{H}$, and Upper Limits of $\mathrm{C}_{3} \mathrm{~N}^{-}$and $\mathrm{C}_{4} \mathrm{H}^{-}$in TMC-1

\begin{tabular}{|c|c|c|c|c|c|c|c|}
\hline \multirow[b]{2}{*}{ Molecule } & \multicolumn{3}{|c|}{ Transition } & \multirow{2}{*}{$\begin{array}{c}\text { FREQUENCY }^{\mathrm{a}} \\
(\mathrm{MHz})\end{array}$} & \multirow{2}{*}{$\begin{array}{c}T_{A}^{*} \\
(\mathrm{mK})\end{array}$} & \multirow{2}{*}{$\begin{array}{c}V_{\mathrm{LSR}} \\
\left(\mathrm{km} \mathrm{s}^{-1}\right)\end{array}$} & \multirow{2}{*}{$\begin{array}{c}\Delta v \\
\left(\mathrm{~km} \mathrm{~s}^{-1}\right)\end{array}$} \\
\hline & $N^{\prime}-N$ & $J^{\prime}-J$ & $F^{\prime}-F$ & & & & \\
\hline \multirow{2}{*}{$\mathrm{C}_{3} \mathrm{~N}^{-}$} & $1-0$ & $\ldots$ & $2-1$ & $9,703.406$ & $<21$ & $\ldots$ & $\ldots$ \\
\hline & $2-1$ & $\ldots$ & $3-2$ & $19,406.536$ & $<12$ & $\ldots$ & $\ldots$ \\
\hline \multirow[t]{9}{*}{$\mathrm{C}_{3} \mathrm{~N}$} & $2-1$ & $5 / 2-3 / 2$ & $5 / 2-3 / 2$ & $19,780.808$ & 203(9) & 5.72 & $0.25(1)$ \\
\hline & $\ldots$ & $\ldots$ & $3 / 2-1 / 2$ & $19,780.823$ & $128(9)$ & 5.54 & $0.21(2)$ \\
\hline & $\ldots$ & $\ldots$ & $5 / 2-5 / 2$ & $19,781.005$ & $47(7)$ & 5.83 & $0.35(6)$ \\
\hline & $\ldots$ & $\ldots$ & $7 / 2-5 / 2$ & $19,781.090$ & $344(9)$ & 5.56 & $0.24(7)$ \\
\hline & $\ldots$ & $\ldots$ & $3 / 2-3 / 2$ & $19,783.537$ & $56(10)$ & 5.62 & $0.16(3)$ \\
\hline & $\ldots$ & $3 / 2-1 / 2$ & $3 / 2-3 / 2$ & $19,797.472$ & $59(8)$ & 5.62 & $0.23(4)$ \\
\hline & $\ldots$ & $\ldots$ & $3 / 2-1 / 2$ & $19,799.959$ & 71(7) & 5.69 & $0.26(3)$ \\
\hline & $\ldots$ & $\ldots$ & $5 / 2-3 / 2$ & $19,800.126$ & $205(8)$ & 5.69 & $0.25(1)$ \\
\hline & $\ldots$ & $\ldots$ & $1 / 2-1 / 2$ & $19,800.971$ & $65(7)$ & 5.65 & $0.27(3)$ \\
\hline \multirow[t]{2}{*}{$\mathrm{C}_{4} \mathrm{H}^{-}$} & $1-0$ & $\ldots$ & $\ldots$ & $9,309.887$ & $<8$ & $\ldots$ & $\ldots$ \\
\hline & $2-1$ & $\ldots$ & $\ldots$ & $18,619.758$ & $<7$ & $\ldots$ & $\ldots$ \\
\hline \multirow[t]{9}{*}{$\mathrm{C}_{4} \mathrm{H}$} & $1-0$ & $3 / 2-1 / 2$ & $1-0$ & $9,493.060$ & $186(7)$ & 5.67 & $0.33(2)$ \\
\hline & $\ldots$ & $\ldots$ & $2-1$ & $9,497.615$ & $605(11)$ & 5.64 & $0.31(7)$ \\
\hline & $\ldots$ & $\ldots$ & $1-1$ & $9,508.005$ & $162(7)$ & 5.61 & $0.33(2)$ \\
\hline & $2-1$ & $5 / 2-3 / 2$ & $2-1$ & $19,014.720$ & $1033(44)$ & 5.72 & $0.26(1)$ \\
\hline & $\ldots$ & $\ldots$ & $3-2$ & $19,015.144$ & $1527(45)$ & 5.74 & $0.26(1)$ \\
\hline & $\ldots$ & $\ldots$ & $2-2$ & $19,025.107$ & $105(20)$ & 5.72 & $0.46(10)$ \\
\hline & $\ldots$ & $3 / 2-1 / 2$ & $1-1$ & $19,044.760$ & $162(22)$ & 5.75 & $0.36(6)$ \\
\hline & $\cdots$ & $\ldots$ & $2-1$ & $19,054.476$ & $1010(30)$ & 5.74 & $0.27(1)$ \\
\hline & $\ldots$ & $\ldots$ & $3-2$ & $19,055.947$ & $440(30)$ & 5.72 & $0.23(2)$ \\
\hline
\end{tabular}

Note.-Position assumed for TMC-1: $\alpha(\mathrm{J} 2000.0)=04^{\mathrm{h}} 41^{\mathrm{m}} 42.49^{\mathrm{s}}, \delta(\mathrm{J} 2000.0)=+25^{\circ} 41^{\prime} 26.9^{\prime \prime}$.

${ }^{a}$ Frequencies of $\mathrm{C}_{3} \mathrm{~N}$ from unpublished measurements in a supersonic molecular beam (estimated $1 \sigma$ uncertainties $5 \mathrm{kHz}$ ), $\mathrm{C}_{4} \mathrm{H}$ frequencies from Gottlieb et al. (1983), and $\mathrm{C}_{4} \mathrm{H}^{-}$from Gupta et al. (2007). 
then used to calculate the vibration-rotation interaction constants $\left(\alpha_{i}\right)$, and to convert the equilibrium rotational constant $B_{e}$ to that of the ground state $B_{0}=B_{e}-\frac{1}{2} \sum_{i} \alpha_{i}$. After our calculation was completed, we learned of an independent calculation of $B_{0}$ at the same level of theory but with a larger basis set (Kolos et al. 2008). As Table 2 shows, the two calculations agree to better than $0.1 \%$ with the measured $B_{0}$.

The formation of anions in our glow discharge is poorly understood. In our earlier work on $\mathrm{CN}^{-}$, we discussed evidence for two mechanisms: (1) radiative electron attachment to the $\mathrm{CN}$ radical, and (2) dissociative attachment to the precursor NCCN. A significant limitation in the interpretation of the $\mathrm{CN}^{-}$observations is that the ratio of $\mathrm{CN}^{-}$to $\mathrm{NCCN}$ cannot be determined, owing to the nonpolarity of NCCN. In the experiments here, the relative concentrations of $\mathrm{C}_{3} \mathrm{~N}^{-}$and $\mathrm{HC}_{3} \mathrm{~N}$ were determined from the measured line intensities under conditions that yielded the most intense lines of the anion. From these measurements, it appears that $\mathrm{C}_{3} \mathrm{~N}^{-}$ may be formed by dissociative attachment to $\mathrm{HC}_{3} \mathrm{~N}$, because the $\mathrm{C}_{3} \mathrm{~N}^{-} / \mathrm{HC}_{3} \mathrm{~N}$ ratio $\left[(3-10) \times 10^{-6}\right]$ is similar in discharges through different precursor gases, and $\mathrm{C}_{3} \mathrm{~N}^{-}$was not observed in a discharge through $\mathrm{NCCN}$ and $\mathrm{N}_{2}$ in which $\mathrm{C}_{3} \mathrm{~N}$ was produced but not $\mathrm{HC}_{3} \mathrm{~N}$.

We have attempted without success to detect the lowest rotational transitions of $\mathrm{C}_{3} \mathrm{~N}^{-}$with our Fourier transform microwave (FTM) spectrometer employing a variety of experimental conditions, and both cyanoacetylene and cyanogen as precursor gases. With either gas mixture, lines of $\mathrm{C}_{3} \mathrm{~N}$ radical are sufficiently strong that transitions of its carbon-13 isotopic species (McCarthy et al. 2003) are readily observed in natural abundance, but there is no evidence for $\mathrm{C}_{3} \mathrm{~N}^{-}$at a level of $10^{-3}$ of the neutral radical.

This failure to find $\mathrm{C}_{3} \mathrm{~N}^{-}$is puzzling; it may mean that anion production in the supersonic beam of the FTM is via radiative electron attachment, and that the efficiency of electron capture is significantly enhanced for radicals with large dipole moments. Lines of isoelectronic $\mathrm{C}_{4} \mathrm{H}^{-}$, for example, were only observed with $\mathrm{He}$ or $\mathrm{H}_{2}$ as a buffer gas (Gupta et al. 2007), even though lines of ground state $\mathrm{C}_{4} \mathrm{H}$ were more than 10 times weaker in $\mathrm{He}$ or $\mathrm{H}_{2}$ than in $\mathrm{Ne}$ or Ar. Detection of $\mathrm{C}_{4} \mathrm{H}^{-}$under these conditions may occur because electron attachment is not from the ground state, which possesses a small dipole moment $(0.87 \mathrm{D})$, but rather from the low-lying ${ }^{2} \Pi$ state $(0.01 \mathrm{eV})$ which has a large dipole moment (4.5 D; see Pachkov et al. 2003) and is thermally populated in the warmer $\mathrm{He}$ or $\mathrm{H}_{2}$ expansions, but is not populated in the $\mathrm{Ne}$ or $\mathrm{Ar}$ expansions. Although $\mathrm{C}_{3} \mathrm{~N}$ has an even higher electron affinity $(4.59 \mathrm{eV})$ than $\mathrm{C}_{4} \mathrm{H}$, the dipole moment of the ground state $(2.9 \mathrm{D})$ is only about half that of the ${ }^{2} \Pi$ electronic state of $\mathrm{C}_{4} \mathrm{H}$, and its first excited electronic state $(0.2 \mathrm{eV})$ is only weakly polar (0.2 D; McCarthy et al. 1995). The apparent absence of $\mathrm{C}_{3} \mathrm{~N}^{-}$lines in the FTM beam may mean that the dipole moment plays a crucial role in determining the rate of electron attachment.

As predicted (e.g., Millar et al. 2000) the abundances of $\mathrm{C}_{6} \mathrm{H}^{-}$ and $\mathrm{C}_{8} \mathrm{H}^{-}$in TMC-1 and $\mathrm{IRC}+10216$, and $\mathrm{C}_{6} \mathrm{H}^{-}$in L1527 are fairly large, representing a good fraction of that of their parent neutral species $(\sim 10 \%)$. On the other hand, the abundance of $\mathrm{C}_{4} \mathrm{H}^{-}$relative to $\mathrm{C}_{4} \mathrm{H}$ is much smaller $(0.025 \%$ in $\mathrm{IRC}+10216$, $0.01 \%$ in L1527, and $<0.004 \%$ in TMC-1; Cernicharo et al. 2007; Agúndez et al. 2008; see $\S 2.2 .2$ ). This may simply be because $\mathrm{C}_{4} \mathrm{H}$ is smaller than $\mathrm{C}_{6} \mathrm{H}$ and $\mathrm{C}_{8} \mathrm{H}$ and has far fewer low-lying vibrational states, making electron attachment less probable. The electron attachment rate coefficients, like all two-body radiative attachment rate coefficients, are difficult to calculate precisely, and are generally evaluated via a statistical theory (see Herbst
1980). Such a theory seems to work for large carbon chains, where nearly every collision between a neutral and an electron yields an anion, but seems to fail for shorter chains: the rate coefficient for $\mathrm{C}_{4} \mathrm{H}+e$ calculated by E. Herbst (2007, private communication) deviates significantly from that derived from the observed $\mathrm{C}_{4} \mathrm{H}^{-}$abundance (see Cernicharo et al. 2007). Further testing of the statistical theory on other short anions is crucial, particularly because this theory is also used to calculate the rates of radiative association between atoms and neutrals, important in astrochemistry.

A crucial parameter that may control the abundance of molecular anions in the interstellar gas is the overall rate of radiative attachment $\left(k_{\text {ratt }}\right)$ for the process $A+e \rightarrow A^{-}+h \nu$. Following Cernicharo et al. (2007), we derived $k_{\text {ratt }}\left(\mathrm{C}_{3} \mathrm{~N}\right)$ from the ratio of the observed abundances of $\mathrm{C}_{3} \mathrm{~N}$ and $\mathrm{C}_{3} \mathrm{~N}^{-}$in the expanding shell of IRC +10216 . On the assumption that the steady state approximation applies and photodetachment may be neglected,

$$
k_{\mathrm{ratt}}=\frac{\left[A^{-}\right]}{[A]} \frac{1}{[e]}\left(k_{\mathrm{aa}}[\mathrm{H}]+k_{\mathrm{neu}}\left[B^{+}\right]\right),
$$

where $[e]$ is the abundance of electrons, $\left[\mathrm{B}^{+}\right]$of cations, and $[\mathrm{H}]$ of atomic hydrogen; $k_{\mathrm{aa}}$ is the rate coefficient for associative detachment by reaction with $\mathrm{H}$; and $k_{\text {neu }}$ for neutralization with cations. We adopt $k_{\text {neu }}=10^{-7} \mathrm{~cm}^{3} \mathrm{~s}^{-1}$ (see, e.g., Smith \& Adams 1979) and $k_{\mathrm{aa}}$ from the measurements of Barckholtz et al. (2001). The abundances of the cations $\left([e] /\left[\mathrm{H}_{2}\right]=\left[B^{+}\right] /\left[\mathrm{H}_{2}\right]=10^{-7}\right.$; Glassgold et al. 1987) and atomic hydrogen $\left([\mathrm{H}] /\left[\mathrm{H}_{2}\right]=10^{-4}\right.$; Glassgold 1996) were estimated for a shell of radius $15^{\prime \prime}$.

From the observed values $\left[\mathrm{C}_{4} \mathrm{H}^{-}\right] /\left[\mathrm{C}_{4} \mathrm{H}\right]=1 / 4200$ and $\left[\mathrm{C}_{6} \mathrm{H}^{-}\right] /\left[\mathrm{C}_{6} \mathrm{H}\right]=1 / 16$ (Cernicharo et al. 2007), we arrive at $k_{\text {ratt }}\left(\mathrm{C}_{4} \mathrm{H}\right)=2 \times 10^{-10} \mathrm{~cm}^{3} \mathrm{~s}^{-1}$ and $k_{\text {ratt }}\left(\mathrm{C}_{6} \mathrm{H}\right)=5 \times 10^{-8} \mathrm{~cm}^{3} \mathrm{~s}^{-1}$. A more thorough time-dependent calculation involving expansion of the envelope and the loss of anions through reactions with neutral atoms other than $\mathrm{H}$ and by photodetachment yields $k_{\text {ratt }}\left(\mathrm{C}_{4} \mathrm{H}\right)=9 \times 10^{-11}(T / 300)^{-0.5} \mathrm{~cm}^{3} \mathrm{~s}^{-1}, k_{\text {ratt }}\left(\mathrm{C}_{6} \mathrm{H}\right)=$ $1.4 \times 10^{-8}(T / 300)^{-0.5} \mathrm{~cm}^{3} \mathrm{~s}^{-1}$, and $k_{\text {ratt }}\left(\mathrm{C}_{8} \mathrm{H}\right)=2.5 \times$ $10^{-8}(T / 300)^{-0.5} \mathrm{~cm}^{3} \mathrm{~s}^{-1}$ (see Agúndez et al. 2008). Similarly, from the observed values of $\left[\mathrm{C}_{3} \mathrm{~N}^{-}\right] /\left[\mathrm{C}_{3} \mathrm{~N}\right]$, we derive $k_{\text {ratt }}\left(\mathrm{C}_{3} \mathrm{~N}\right)=$ $1.9 \times 10^{-9}(T / 300)^{-0.5} \mathrm{~cm}^{3} \mathrm{~s}^{-1}$ from our time-dependent model calculations. The electron attachment rate coefficient derived for $\mathrm{C}_{3} \mathrm{~N}$ is then $\sim 20$ times larger than that of $\mathrm{C}_{4} \mathrm{H}$.

This value of $k_{\text {ratt }}\left(\mathrm{C}_{3} \mathrm{~N}\right)$ may be compared with that derived by Petrie \& Herbst (1997), who calculated the total energies and enthalpies of formation of $\mathrm{C}_{3} \mathrm{~N}^{-}, \mathrm{C}_{3} \mathrm{~N}$, and $\mathrm{CCCNH}$; and the intensities and vibrational frequencies of $\mathrm{C}_{3} \mathrm{~N}^{-}$. They derived $k_{\text {ratt }}\left(\mathrm{C}_{3} \mathrm{~N}\right)=(2-4) \times 10^{-10}(T / 300)^{-0.5} \mathrm{~cm}^{3} \mathrm{~s}^{-1}$, depending on whether they used the calculated or the experimental electron affinity of $\mathrm{C}_{3} \mathrm{~N}$. This is almost an order of magnitude smaller than the apparent rate derived from our measured $\mathrm{C}_{3} \mathrm{~N}^{-}$ abundance.

Another possible pathway for the formation of $\mathrm{C}_{3} \mathrm{~N}^{-}$is dissociative attachment to HNCCC (a metastable isomer of cyanoacetylene) first proposed by Petrie \& Herbst (1997),

$$
\mathrm{HNCCC}+e \rightarrow \mathrm{CCCN}^{-}+\mathrm{H} .
$$

The column density of HNCCC derived from recent observations of the $J=9-8$ through $12-11$ lines in IRC +10216 with the IRAM telescope, $7 \times 10^{11} \mathrm{~cm}^{-2}$, is about 500 times less than that of $\mathrm{C}_{3} \mathrm{~N}$ (J. Cernicharo et al. 2008, in preparation). Therefore, reaction (2) would have to be at least 500 times faster than reaction (1) to account for the observed $\left[\mathrm{C}_{3} \mathrm{~N}^{-}\right] /\left[\mathrm{C}_{3} \mathrm{~N}\right]$ ratio in $\mathrm{IRC}+10216$. 
Such a high rate of $\geq 10^{-6} \mathrm{~cm}^{3} \mathrm{~s}^{-1}$ for reaction (2) seems implausible. HNCCC is relatively abundant in TMC-1 (Snyder et al. 2006) but $\mathrm{C}_{3} \mathrm{~N}^{-}$is not detected there, implying that reaction (2) may not be a significant channel for the formation of $\mathrm{C}_{3} \mathrm{~N}^{-}$in cold clouds. If reaction (1) is the only efficient path for the formation of $\mathrm{C}_{3} \mathrm{~N}^{-}$in the interstellar gas, then $k_{\text {ratt }}\left(\mathrm{C}_{3} \mathrm{~N}\right)$ derived from the measured abundance of $\mathrm{C}_{3} \mathrm{~N}^{-}$in IRC+10216 is the true rate of radiative attachment, which we have shown is about an order of magnitude greater than that predicted by Petrie \& Herbst (1997).

The laboratory identification of new molecular ions in the millimeter-wave band is much easier when it is possible to readily distinguish ionic lines from those of neutral molecules. The technique of velocity modulation provides excellent discrimination between ions and neutrals in the IR band (Stephenson \& Saykally 2005), but when lines of the ions are observed by this technique in the millimeter-wave band they are about 6 times weaker than those observed in a normal DC glow discharge (because the Doppler shift from the ion drift is much less than the pressure broadened line width; Savage \& Ziurys 2005; see also Fig. 3). If the sensitivity of our millimeter-wave spectrometer can be increased moderately, say by a factor of 5, velocity modulation may become a powerful general technique for the detection of new molecular anions.

Other anions of astrophysical interest may be detected by the present technique. Five good candidates are $\mathrm{CH}_{3} \mathrm{CC}^{-}$(1-propynyl),

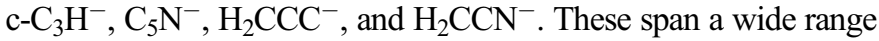
of binding energy and dipole moment: linear $\mathrm{C}_{5} \mathrm{~N}^{-}$and the symmetric top $\mathrm{CH}_{3} \mathrm{CC}^{-}$have large dipole moments and binding energies that are comparable to that of $\mathrm{C}_{6} \mathrm{H}^{-}$, but the binding energies of the others are $\leq 2.0 \mathrm{eV}$. The rotational constants and leading centrifugal distortion constants of $\mathrm{H}_{2} \mathrm{CCC}^{-}$and $\mathrm{H}_{2} \mathrm{CCN}^{-}$ were derived by autodetachment spectroscopy (Yokoyama et al. 1996; Lykke et al. 1987), so the search for the rotational lines can be restricted to a fairly narrow frequency range. Observations of these five molecular anions may allow astronomers to better determine the electron density in the interstellar gas, when the dependence of the cross sections for electron attachment and photodetachment on dipole moment and electron affinity have been determined.

For new observations, the highest priority in our view should be given to the discovery of better astronomical sources for negative molecular ions in a wide range of objects, starting with a deep survey of $\mathrm{C}_{6} \mathrm{H}^{-}$, the most readily observed molecular anion to date. It is highly implausible that with IRC+10216, TMC-1, and recently L1527 the best anion sources in the entire Galaxy have been found; it is more reasonable to assume instead that this limitation is largely the well-known selection effect of observers devoting their limited observing time on big telescopes to the few sources which have worked in the past. The same selection effect was encountered in the early study of interstellar molecules. Breaking free of this straitjacket is worth a substantial amount of observing time on the largest radio telescopes. It is not premature to suggest that such a survey should be extended to some of the more plausible extragalactic sources.

We are grateful for helpful suggestions from E. Herbst, W. Klemperer, and T. Oka. We are particularly pleased to acknowledge the advice and support of J. F. Stanton, and the generous assistance of Professor W. von E. Doering and Dr. Xin Zhao with the synthesis of cyanoacetylene. This work is supported by National Science Foundation grant CHE-0701204 and NASA grant NNX08AE05G; support for H. G. is provided by the Robert A. Welch Foundation and through NSF grant CHE-0710146 to J. F. Stanton at the University of Texas. S. B. is grateful to the Harvard College Observatory for a Menzel fellowship. The National Radio Astronomy Observatory (NRAO) is a facility of the National Science Foundation operated under cooperative agreement by Associated Universities, Inc.

\section{APPENDIX A}

Cyanoacetylene $\left(\mathrm{HC}_{3} \mathrm{~N}\right)$ was synthesized $20 \mathrm{~g}$ at a time with a yield of about $70 \%$ by a procedure similar to that described by Miller \& Lemon (1967). To ensure a high yield of propiolamide $\left(\mathrm{HCCCONH}_{2}\right.$, the product of the first step in the synthesis), the large excess of $\mathrm{NH}_{3}$ was removed by flushing the reaction vessel with $\mathrm{N}_{2}$ and bubbling the $\mathrm{NH}_{3} / \mathrm{N}_{2}$ mixture through concentrated HCl. Methanol $\left(\mathrm{CH}_{3} \mathrm{OH}\right)$ present as a by-product in the reaction was then pumped away. The sample was stored indefinitely at $-20 \mathrm{C}$ with no discernible evidence of polymerization, but during the experiment $\mathrm{HC}_{3} \mathrm{~N}$ was maintained at a slightly higher temperature $(-10 \mathrm{C})$ to provide sufficient vapor pressure ( $\sim 60$ torr; Dannhauser \& Flueckinger 1963). A flow rate of $3-4 \mathrm{~cm}^{3}$ minute ${ }^{-1}$ (estimated with a mass flow controller), yielded near optimum line intensities of the $\mathrm{C}_{3} \mathrm{~N}$ radical and a reasonable rate of $\mathrm{HC}_{3} \mathrm{~N}$ consumption of approximately $0.5 \mathrm{~g}$ hr ${ }^{-1}$. In most experiments described here the flow of $\mathrm{HC}_{3} \mathrm{~N}$ vapor was maintained with a manual metering valve because it was found that in a few days running the electronic flow controller becomes clogged. As a result, the flow rate of $\mathrm{HC}_{3} \mathrm{~N}$ is less certain than that of the other precursor gases, owing to changes in the vapor pressure due to variations in the temperature of the sample bath.

\section{APPENDIX B}

Shown in Figure 1 are sample spectra and rotational energy level diagrams of $\mathrm{C}_{3} \mathrm{~N}$ and $\mathrm{C}_{3} \mathrm{~N}^{-}$. The spin rotation doublet splittings in the energy level diagram of $\mathrm{C}_{3} \mathrm{~N}$ are magnified to illustrate the higher density of levels in the ${ }^{2} \Sigma$ electronic ground state of the radical. Electron attachment to the radical results in the collapse of the spin doublets, simplifying the spectrum of the anion to that of closed shell linear molecule in a ${ }^{1} \Sigma$ ground state. The enhancement of the line intensities of $\mathrm{C}_{3} \mathrm{~N}^{-}$relative to those of $\mathrm{C}_{3} \mathrm{~N}$ by a factor of 2.4 results mainly from the collapse of the spin doublets of the radical, since the dipole moment of the anion $(3.1 \mathrm{D})$ is only slightly larger than that of the radical (2.85 D; McCarthy et al. 1995). As Figure 2 shows, this spectroscopic enhancement of $\mathrm{C}_{3} \mathrm{~N}^{-}$relative to $\mathrm{C}_{3} \mathrm{~N}$ is independent of temperature for the typical astronomical sources where molecular anions have been observed.

\section{REFERENCES}

Agúndez, M., et al. 2008, A\&A, 478, L19

Barckholtz, C., Snow, T. P., \& Bierbaum, V. M. 2001, ApJ, 547, L171

Brünken, S., Gupta, H., Gottlieb, C. A., McCarthy, M. C., \& Thaddeus, P.

2007, ApJ, 664, L43
Cernicharo, J., Guélin, M., Agúndez, M., Kawaguchi, K., McCarthy, M. C., \& Thaddeus, P. 2007, A\&A, 467, L37

Cernicharo, J., Guélin, M., \& Kahane, C. 2000, A\&AS, 142, 181

Dannhauser, W., \& Flueckinger, A. F. 1963, J. Chem. Phys., 38, 69 
Ding, Y. H., Huang, X. R., Lu, Z. Y., \& Feng, J. N. 1998, Chem. Phys. Lett., 284, 325

Douglas, A. E., \& Herzberg, G. 1941, ApJ, 94, 381

Glassgold, A., E. 1996, ARA\&A, 34, 241

Glassgold, A., E., Mamon, G., A., Omont, A., \& Lucas, R. 1987, A\&A, 180, 183

Gottlieb, C. A., Brünken, S., McCarthy, M. C., \& Thaddeus, P. 2007, J. Chem. Phys., 126, 191101

Gottlieb, C. A., Gottlieb, E. W., Thaddeus, P., \& Kawamura, H. 1983, ApJ, 275, 916 Graupner, K., Merrigan, T. L., Field, T. A., Youngs, T. G. A., \& Marr, P. C. 2006, New J. Phys., 8, 117

Guélin, M., Green, S., \& Thaddeus, P. 1978, ApJ, 224, L27

Guélin, M., Lucas, R., \& Cernicharo, J. 1993, A\&A, 280, L19

Guélin, M., \& Thaddeus, P. 1977, ApJ, 212, L81

Gupta, H., Brünken, S., Tamassia, F., Gottlieb, C. A., McCarthy, M. C., \& Thaddeus, P. 2007, ApJ, 655, L57

Harland, P. W., \& Maclagan, R. G. A. R. 1987, Faraday Trans., 83, 2133

Herbst, E. 1980, ApJ, 237, 462

Kawaguchi, K., Kasai, Y., Ishikawa, S., \& Kaifu, N. 1995, PASJ, 47, 853

Kawaguchi, K., et al. 2007, PASJ, 59, L47

Kolos, R., Gronowski, M., \& Botschwina, P. 2008, J. Chem. Phys., in press

Lykke, K. R., Neumark, D. M., Anderson, V. J., \& Lineberger, W. C. 1987, J. Chem. Phys., 87, 6842

McCarthy, M. C., Fuchs, G., Kucera, J., Winnewisser, G., \& Thaddeus, P. 2003, J. Chem. Phys., 118, 3549
McCarthy, M. C., Gottlieb, C. A., Gupta, H., \& Thaddeus, P. 2006, ApJ, 652, L141

McCarthy, M. C., Gottlieb, C. A., Thaddeus, P., Horn, M., \& Botschwina, P. 1995, J. Chem. Phys., 103, 7820

Mikami, H., Yamamoto, S., Saito, S., \& Guélin, M. 1989, A\&A, 217, L5

Millar, T. J., Herbst, E., \& Bettens, R. P. A. 2000, MNRAS, 316, 195

Miller, F. A., \& Lemon, D. H. 1967, Spectrochim. Acta, 23A, 1415

Pachkov, M., Pino, T., Tulej, M., Guethe, F., Tikhomoirov, K., \& Maier, J. P. 2003, Mol. Phys., 101, 583

Petrie, S., \& Herbst, E. 1997, ApJ, 491, 210

Remijan, A. J., et al. 2007, ApJ, 664, L47

Savage, C., \& Ziurys, L. M. 2005, Rev. Sci. Instrum., 76, 043106

Smith, D., \& Adams, N., G. 1979, in Proc. Kinetics of Ion-Molecule Reactions, ed. P. Ausloos (New York: Plenum Press), 40, 345

Snyder, L. E., Hollis, J. M., Jewell, P. R., Lovas, F. J., \& Remijan, A. J. 2006, ApJ, 647, 412

Stanton, J. F., \& Gauss, J. 2000, Int. Rev. Phys. Chem., 19, 61

Stephenson, S. K., \& Saykally, R. J. 2005, Chem. Rev., 105, 3220

Thorwirth, S., Müller, H. S. P., \& Winnewisser, G. 2000, J. Mol. Spectrosc., 204, 133

Yokoyama, K., Leach, G. W., Kim, J. B., \& Lineberger, W. C. 1996, J. Chem. Phys., 105, 10696

Note added in proof.-After submission of this paper, we observed the five lowest rotational transitions of $\mathrm{C}_{3} \mathrm{~N}^{-}$by means of Fourier transform microwave (FTM) spectroscopy. These new measurements provide frequencies of the hyperfine-split components which are accurate to better than $0.2 \mathrm{ppm}$, i.e., a fraction of a linewidth in TMC-1. The nitrogen quadrupole coupling constant derived here, $e Q q=-3.248 \pm 0.005 \mathrm{MHz}$, is in excellent agreement with the theoretical prediction of $-3.3 \mathrm{MHz}$. A complete account of the FTM measurements will be presented elsewhere. 